\title{
Walls of Well-Being (WOWs): a Pilot Study of a New Methodology to Explore Children's and Adolescents' Perceived Sources of Happiness
}

\author{
Mark D. Holder ${ }^{1}$ • Holli-Anne Passmore ${ }^{1}$. \\ Catherine Broom ${ }^{2} \cdot$ Stephen Berg ${ }^{2}$ Eric $\mathrm{Li}^{3}$. \\ Ross Hickey $^{4} \cdot$ Christopher Martin $^{2}$
}

Accepted: 4 May 2017 / Published online: 26 June 2017

(C) Springer International Publishing AG 2017

\begin{abstract}
Lay theories are everyday explanations and attributions given for psychological phenomena. They are important because they affect people's behaviours and cognitions. Lay theories have typically been studied using interviews and surveys of individuals. We describe a pilot study that employed a new, community-based, methodology that we used to explore children's and adolescents' lay theories of happiness. We collected 802 responses to the phrase "I feel happy when " which was stencilled repeatedly on large walls we called Walls of Well-Being (WOWs) installed in a kindergarten-elementary school and a junior-high school. An interpretive, grounded theory approach for coding these qualitative data was used. Five main themes emerged in the children/adolescents' responses: Activities, Relationships, Other Oriented, Personal Feelings, and Receiving. Chi-square analyses revealed significant differences in the prevalence of response themes between the two schools demonstrating that the WOWs are sensitive to community differences. Advantages and disadvantages of the WOWs methodology are discussed as well as suggestions for mitigating disadvantages in future studies utilizing WOWs. This new method holds promise as an assessment tool that could be applied across a wide range of psychological phenomena (e.g., gratitude and hope) and environments (e.g., hospitals and businesses).
\end{abstract}

Mark D. Holder

mark.holder@ubc.ca

1 University of British Columbia Psychology, IKBSAS, Arts 320, 3333 University Way, Kelowna, BC V1V 1V7, Canada

2 University of British Columbia, Education, Vancouver, BC, Canada

3 University of British Columbia, Management, Vancouver, BC, Canada

4 University of British Columbia, Economics, Vancouver, BC, Canada 
Keywords Happiness · Lay theories · Children · Adolescents · Qualitative research · Positive psychology interventions

Across continents and cultures, happiness is a strongly desired trait for children. This was demonstrated by Diener and Lucas (2004) who surveyed over 10,000 adults from 48 countries on six continents. Most of these adults desired high levels of happiness for their children. Yet, despite this near-universal recognition of the importance of children's happiness, research on understanding children's and youth's conception of what contributes to their own happiness, or how happiness is understood by children and youth themselves, is still relatively meager.

Happiness has been conceptualized as a major component of the positive affect dimension of well-being which also includes negative affect and a cognitive dimension related to life satisfaction (Diener 2000). Research has suggested multiple way of attaining happiness and one influential model has identified five pathways: pleasure, engagement, relations, meaning, and achievement (Peterson and Seligman 2004). However, lay person's definitions of happiness can differ from the definitions formulated by researchers, and lay person's perception of what contributes to happiness does not always reflect the sources identified in research and by models. Moreover, the meaning of happiness shifts over the life course (Mogilner et al. 2012; Mogilner et al. 2011), and lay theories appear to change with age. Therefore, further research is warranted to examine lay theories of happiness for different age groups. Thus, we sought to examine the efficacy of a new community-based methodology to explore children's and youth's (ages 5 to 15) conceptualizations of sources of happiness.

Although recent research has identified correlates of children's and youth's well-being (see Holder 2012), empirical work on how children and youth understand what contributes to their happiness and well-being, their lay theories, is scarce. Lay theories include the explanations and attributions that people give for psychological phenomena without the input of formal scientific findings and theories. The study of lay theories is important because such theories govern the way people understand the world around them and can guide decision making and behavior (Furnham 2001; Tong and Chiu 2002). For example, lay theories can impact the setting and achieving of academic (Robins and Pals 2002) and personal goals (Mukhopadhyay and Johar 2005). Lay theories are also important because they can be compared to scientific theories (particularly when the theories are psychological and social in nature) and can contribute to the development of scientific theories (see Furnham 2001; Levy et al. 2006; Sternberg et al. 1981).

Understanding lay theories in children has been recognized as important. Despite focusing much of his career on cognitive development, Piaget suggested that the lay theories children construct might be as important as cognition (Piaget and Garcia 1989). Similar to adults, children's lay theories influence behavior. For example, children who endorse a view that individual characteristics change, compared to children who endorse a view that individual attributes are more fixed, judge others less readily and show increased flexibility when rating others (Erdley and Dweck 1993; Levy and Dweck 1999). Additionally, children who ascribed to a view that individuals' attributes change, recognized greater similarity between themselves and less fortunate groups, and were more likely to volunteer to help these groups (Karafantis and Levy 2004). 
In a study of lay theories of happiness, people with an average age of 18 years attributed happiness to six underlying factors (Furnham and Cheng 2000). These factors, which included personality traits, social support, and optimism, were similar to the factors identified by empirical work as actually relating to happiness. Factors such as having a higher level of education attainment and being more intelligent were rated as contributing less to happiness which is in agreement with current research. Lay theories of happiness are important because what people believe contributes to happiness will likely influence how they behave to attain happiness (Furnham and Cheng 2000); if lay theories wrongly ascribe causal relations, people may be ineffective at increasing their happiness.

Lay theories of happiness, and their relationship with the positive affect people experience, differ between adults and adolescents (Bojanowska and Zalewska 2016). Additionally, Dube et al. (1998) reported that both young adults and their parents believe that internal factors influence subjective well-being more than external factors, however parents attribute a greater role to external factors than do young adults. Given that lay theories vary with age, a comprehensive exploration of lay theories requires the study of children and adolescents.

Though most studies of lay theories of positive phenomena have focused on adults, a few studies have included younger populations. For example, children in India identified parents, followed by teachers and peers, as contributing most to their happiness (Sidana et al. 1976). However, these results may have limited generalizability; the study is older, based on a small sample, and only the contributions that other people made to children's happiness were assessed. More recent research examining both positive and negative emotions, found that children attributed happiness to receiving what they wanted (Harter and Whitesell 1989). Rigby and Huebner (2005) reported that adolescents' lay theories involving good events were related to life satisfaction, and Thoilliez (2011) found that when 6 to12 year old children were asked about what contributes to their happiness, they emphasized family and friendships.

\section{The Current Pilot Study}

Most work on lay theories in children and adolescents has used traditional research methods such as administering questionnaires (Rigby and Huebner 2005) or one-onone interviews (Thoilliez 2011). These methods only engage children and adolescents at the individual level, and they can be time consuming. Therefore, we sought to examine the efficacy of a new community-based methodology to explore children's and youth's (ages 5 to 15) conceptualizations of happiness. This method was inspired by the artist Candy Chang who installed chalk boards in public places with the phrase "Before I die I want to ..." stenciled repeatedly on each board. In the dozens of countries where these boards were installed, members of each community completed this phrase despite that there were no extrinsic incentives for doing so. Indeed, these boards were quickly filled with responses written on every free space available on the boards. Similarly, we installed boards (WOWs) in schools. On each WOW, the phrase "I feel happy when ..." was repeatedly stenciled. Students were free to complete the phrase on the WOWs. In this way, the WOWs acted as a novel procedure with which to collect qualitative data on what children and adolescents identified as contributing to their happiness. 


\section{Method}

\section{Participants}

One kindergarten-elementary (K to Grade 6; 244 students) and one junior-high school (Grades 7-9; 140 students) participated in this pilot project. Compared to the juniorhigh school, the student body of the kindergarten-elementary school was more culturally diverse with an overall lower socio-economic status. While the kindergartenelementary school was a public, non-denominational school, the junior-high school was a private, faith-based institution with an educational philosophy based on a Godcentered view of people and truth as presented in the Bible.

\section{The Research Team}

Our research team was an interdisciplinary group of researchers from the faculties/ departments of Psychology, Education, Economics, and Management at the University of British Columbia. The combined team has many years of experience conducting qualitative research in educational (and other) settings, in addition to expertise in the domain of positive psychology and happiness and well-being in children.

\section{Procedure}

WOWs were originally installed in centrally located spaces (hallways and foyers) at the two schools. This placement afforded all students the opportunity to complete on the WOWs the sentence, "I feel happy when ". Students could write on the WOWs at a time of their choosing which could be either when they were alone or with others. The WOWs were not moved at the junior-high school, but school staff moved the WOWs at the elementary school outside during recess periods. The WOWs were accessible at the schools for a period of two weeks in early June. The researchers instructed staff at the schools to allow the students free, undirected choice in deciding if, when, and what, to write on the WOWs. The WOWs were photographed and taken down at the end of two-weeks.

\section{Analytic Methodology}

All responses written on the WOWs from both schools were recorded and classified by line entry and school. The literal responses were recorded (e.g., spelling mistakes, capitalization) and any pictures or graphics that were drawn beside the responses were noted such as: I am happy when "im with my dog! $\bullet=)$ ". Additionally, to facilitate coding, interpretative notes were added as necessary. For instance, for the WOW response of "Pewdie Pie puts out new ideas," an interpretive note was made, "Swedish video game commentator".

Coding of the written WOW responses was conducted utilizing an interpretative, grounded theory approach (Corbin and Strauss 2008; Glaser 1992). Coding categories were determined based on a conventional content analysis approach. This approach allowed prevalent codes/themes to emerge from the children's and youth's responses, rather than a pre-determined framework of themes being imposed upon the responses, 
such as in a directed content analysis. Coding was an iterative process involving a subset of the research team independently coding a sample of the WOW responses, meeting as a group to discuss emergent codes/themes, again independently coding a sample of WOW responses, and then reconvening to discuss the coding categories. A trained research assistant, who attended the group meetings, then coded the complete set of WOW responses.

Based on the coded data, the research team discussed and identified repeated concepts, carried out constant comparisons, identified which themes emerged at this step, and analyzed the relationships between the data, concepts, and themes. Multiple data interpretations were conducted at various levels using theoretical sampling; context and process were considered. Heuristic tools such as a coding table were used; attention was paid to the use of feelings, contextual factors, and time sequencing (Corbin and Strauss 2008). Chi-square data analyses were performed on the observed frequencies of emergent themes, and the contingency table examined in order to identify significant differences between responses at the two schools.

\section{Findings from the Pilot Study of WOWs}

A total of 802 responses were written on the WOWs installed at the two schools (see Figs. 1 and 2). Of these responses, 15 did not fall into an identifiable category/theme, 5 were written by teachers (e.g., I am happy when "my students learn"), and 54 were either illegible or ambiguous as to meaning (e.g., "King Mutter", and "BCUSTHEMASFESAPSO DEEKID”). If a response contained more than one theme,

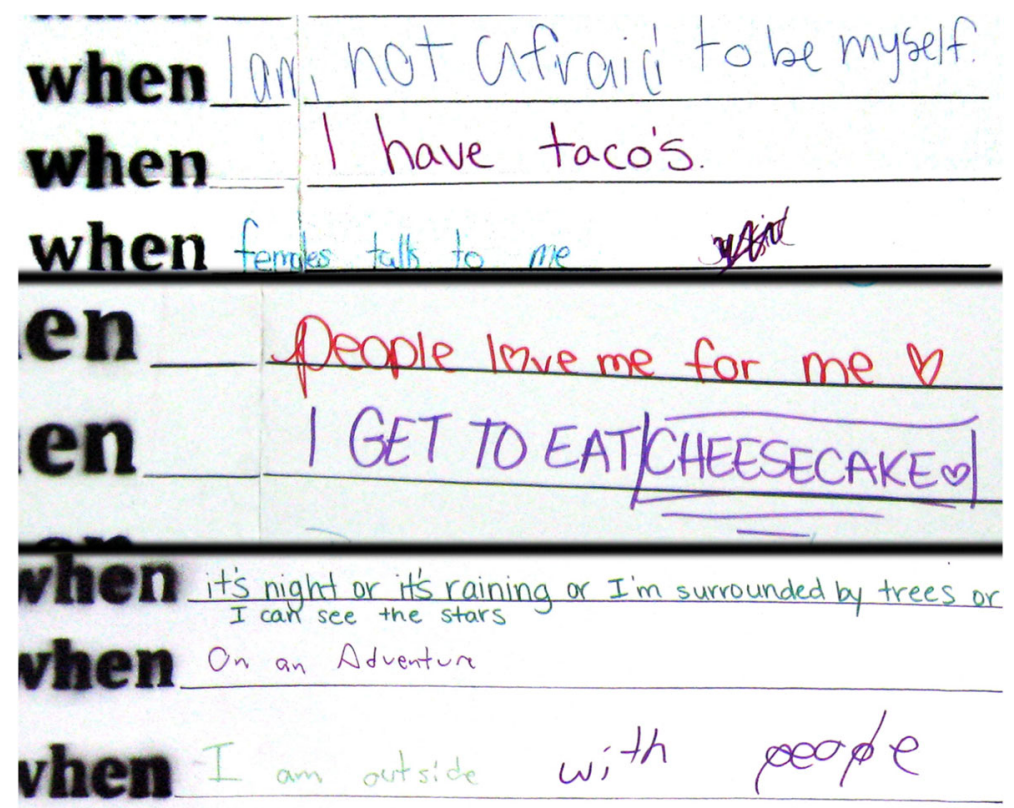

Fig. 1 Examples of responses written on the Walls of Well-Being (WOWs) to complete the phrase "I feel happy when 


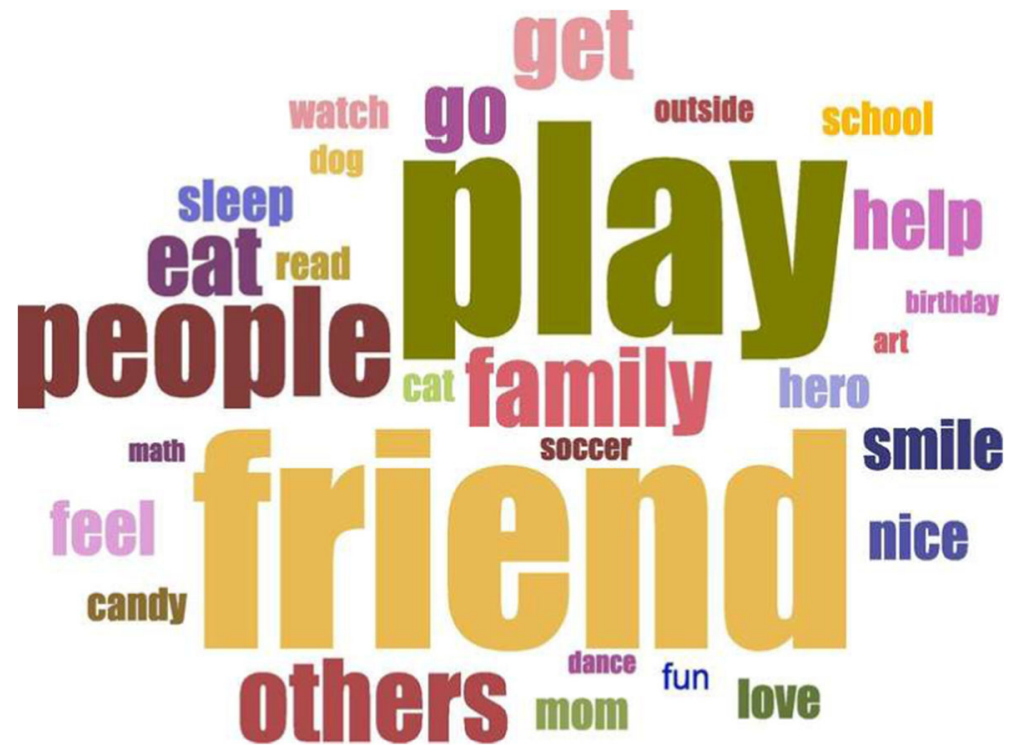

Fig. 2 Visual word cloud of top 30 keywords written on the WOWs. Font size is proportional to the frequency with which the word was written on the WOWs. Only those words that had a frequency greater than five were used. Produced online at http://jasondavies.com/wordcloud

it was classified and counted under both themes. Thus, the analyses were conducted on 757 total responses.

Five main themes emerged: Activities (350 responses, $46 \%$ of total), Relationships (206 responses, 27\%), Other Oriented (81 responses, 11\%), Personal Feelings ( 81 responses, 11\%), and Receiving (39 responses, 5\%). Additionally, each main theme was categorized into subthemes shown in Table 1 which includes response counts for themes and subthemes for each school.

\section{Data Analysis of Identified Themes}

Although we could not match age to specific responses on the wall, we did compare responses from the students at the two schools. A chi-square analysis of the main themes revealed that school had a significant effect on the responses provided $\chi^{2}(4$, $N=757)=45.86, p<.001$, Cramer's $V=.25$ (indicating a medium effect size; Gravetter and Wallnau 2008). Older students' responses were less likely than younger students' to be related to the themes of Relationships $(z=-3.3)$ and Other Oriented $(z=-3.3)$, and more likely to be related to the themes of Activities $(z=2.7)$ and Personal Feelings $(z=2.0)$. School did not significantly differ in the likelihood of responding with a theme related to Receiving $(z \mathrm{~s}=.0 .9,1.5)$ [ $z \mathrm{~s}$ reported are standardized residuals].

Younger students were more than twice as likely as older students to write responses related to Relationships than Activities themes $(\mathrm{RR}=2.20, z=4.26, p<.001,95 \%$ $\mathrm{CI}[1.53,3.16])$, and more than five times as likely as older students to write responses related to Other Oriented themes than Activities themes $(\mathrm{RR}=5.4, z=3.76, p<.001$, $95 \% \mathrm{CI}[2.24,13])$. Older students were twice as likely as younger students to write responses involving Personal Feelings themes than Other Oriented themes $(R R=2.07$, 


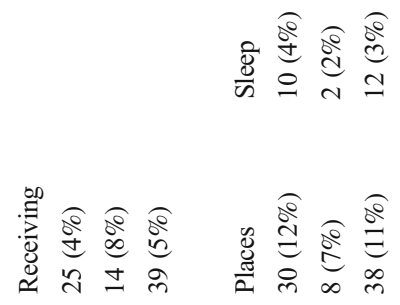

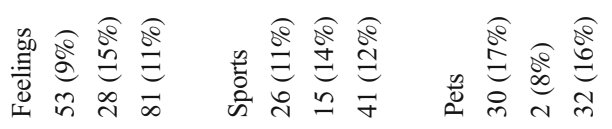

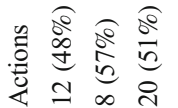
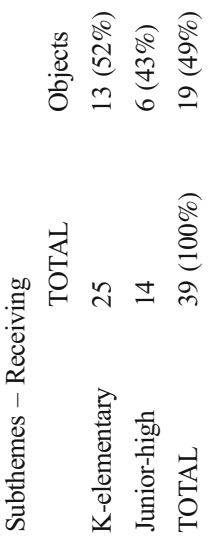

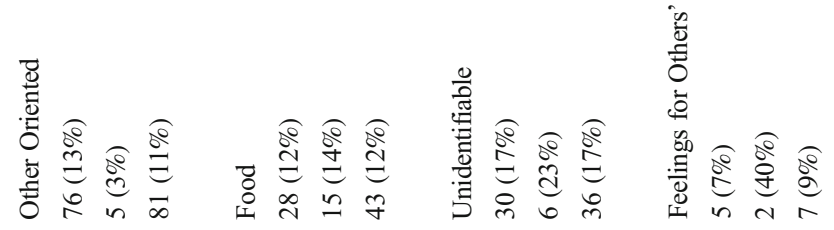

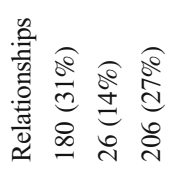

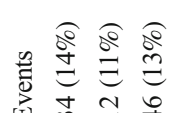

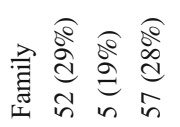

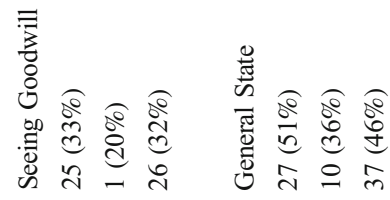

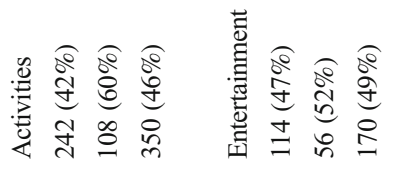

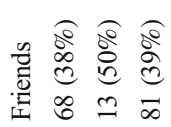

言

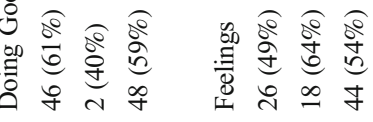

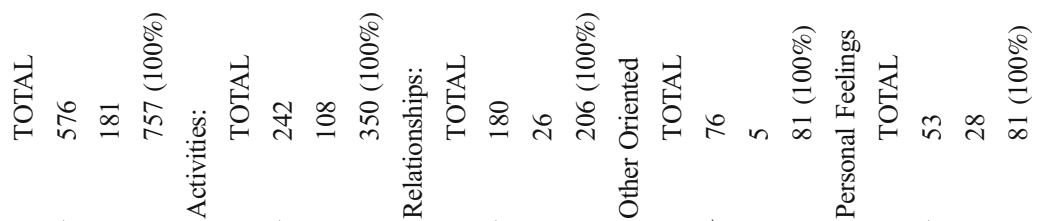

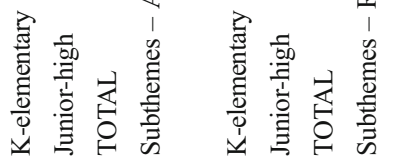

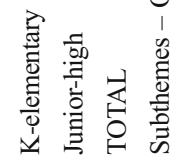

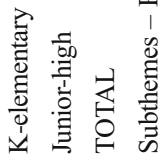

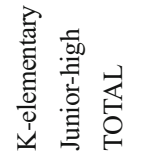


$z=5.64, p<.001,95 \% \mathrm{CI}[1.61,2.66])$, and over twice as likely to write responses involving Personal Feelings themes than Relationships themes $(\mathrm{RR}=2.28, z=4.62$, $p<.001,95 \% \mathrm{CI}[1.61,3.23])$.

Additional chi-square analyses revealed that within the main themes, the subtheme responses were not significantly influenced by school: Activities: $\chi^{2}(5$, $N=350)=4.64, p=.47$; Relationships: $\chi^{2}(3, N=206)=3.34, p<.34$; Other Oriented: $\chi^{2}(2, N=81)=6.64, p<.07$; Personal Feelings: $\chi^{2}(1, N=81)=1.71$, $p<.24$; Receiving: $\chi^{2}(1, N=39)=0.30, p<.74$.

\section{Descriptive Analysis of Identified Themes}

Activities For both schools, Activities emerged as the foremost theme of happiness. Students connected happiness to various types of activities such as entertainment (e.g., "I watch fairy tails"), special events (e.g., "it's my birthday", "I am celebrating Aboriginal Day"), food consumption (e.g., "I eat tacos", "I eat"), sports (e.g., "I play soccer", "I am riding my bike"), travelling to or visiting places (e.g., "I'm at church", "I am on an adventure"), and sleep (e.g., "I get a good sleep, which is rare"; "I sleep all day long"). Among these Activities-theme responses, most students connected happiness to different forms of entertainment, particularly electronics-related. Playing videoor computer games, watching TV or movies, and playing games or engaging in other activities on mobile devices were some of the common forms of electronic-oriented entertainment mentioned by students (e.g., "I Minecraft", "I watch Vines", "I play on the computer").

"Playing" and "reading" were other common forms of entertainment activities that were commonly mentioned. Typical examples include, I feel happy when "I play games", "I read Harry Potter". Examples of other responses related to entertainment included building Lego structures, drawing, or writing stories.

Following entertainment, sports, special events, and food consumption were the next most popular listed happiness-inducing activities. Responses involving each of these three categories of activities were mentioned in similar numbers. Team sports including basketball, soccer, and volleyball, as well as group sports activities including paintball and dancing, were mentioned by the students. The popularity of team or group sports activities reflects both the satisfaction that children and youth experience during these activities, and expresses the happiness that students receive from being on a team with their peers. These findings echo our findings below in the Relationship-happiness section, in which most of the students stated that they felt happiness when they were with their friends or family members.

Events such as birthdays, weekends, or holidays were some of the time-oriented activities that students associated with their happiness. Students also connected their happiness to travelling to, or visiting, places such as school, theme parks, and playgrounds. Seasonal changes and weather conditions were other occasions that students connected to their happiness (e.g., "it's spring", "the sun shines", and "I see a rainbow"). Being outside was also a popular response (e.g., "I'm camping", "I go outside", and "I'm surrounded by trees and I can see the stars"). Food consumption was another type of activity that students identified as affecting their happiness. Snacks such as pizza, tacos, and hotdogs, and sugary food such as candies, cake, and donuts were noted by students. 
School-related activities were often mentioned in conjunction with other activities. Students viewed school-related activities in two different ways. Some of the students enjoyed going to school and attending certain classes (e.g., "I read and do math and art", and "I am learning"); while others considered "work-free" moments to be happy (e.g., "I have no homework or exams"). Some students also mentioned that their performance at school affected their happiness (e.g., "I get 20 out of 20 on my spelling test").

Relationships The second most common happiness theme that emerged was Relationships. Most comments within this theme mentioned family or friends. For example, students indicated they were happy when they were with a particular person (a friend or a family member) or when they played with their friends. Typical comments were: "I feel happy when I'm with (family or friend name)" or "I feel happy when I play with__ (friend or family member)." Many students commented that being with their pets made them happy (e.g., "playing with my dog eva", "see my two birds", and "I am dressing my kitty like a princess although it's a boy”.

Other Oriented The majority of responses in this happiness theme were related to the concepts of "sharing" and "helping someone"; other responses frequently mentioned prosocial behaviors such as "being kind", "doing nice things for others", and "I am a good friend". Several kindergarten-elementary school students mentioned they were happy when they were involved in a school program that encourages students to help each other. Some students felt happy when their own actions "made other people feel good". Many students responded that observing other people doing good deeds made them feel happy. Examples of these comments are "people are nice to others", "others share", and "people smile". Some students stated that they felt happy when "other people are happy too".

Personal Feelings Equal to the number of Other Oriented responses, were responses that referred to personal feelings or general states of being. Many students associated happiness with how they felt. For example, when they felt "proud" after they had accomplished a difficult task (such as math), when they felt "inspired", or when they felt "loved and valued" for being themselves. Some of the students from the faith-based junior-high school made religious comments such as feeling happy when "God loves me", "I feel close to Jesus", or "I feel God's presence".

While half the responses noted specific emotions, the other responses were more global in reference. For example, some students reported feeling happy when conditions were good such as "I have a good day" or "Everything is awesome," or when they felt effective in their lives (e.g., "I feel like a boss" or "I am awesome"). Many students simply stated that they felt happy when they are happy.

Receiving A small number of responses referenced a theme of receiving something from someone. Responses were divided evenly between those who referred to receiving an object and those who referred to receiving an action. Currency was the most frequent object that participants commented on; "I get money" or "getting paid" were frequently written. Other comments included receiving objects such as "getting candy" or "I get toys." 
Several comments made by the elementary school students referred to being happy when they received actions such as "getting hugs" and "people saying hi to me." Other comments included "people playing with me" and "teacher helping me learn." In the junior-high school, comments such as "people taking time to get to know me" and "calling me cool" were written.

\section{Discussion}

The present research was a preliminary exploration of the feasibility of a novel approach to assess children's lay theories through the installation of WOWs in schools. It is important to note that specific findings from this pilot project should be considered preliminary and are the first step in the validation of the WOW methodology.

The use of WOWs to assess children's lay theories of happiness appears promising as our pilot project's findings converged with findings of previous studies in which more traditional methods were employed, and with theories of well-being. For example, previous research assessing children's lay theories of emotions that utilized more traditional methods, such as structured interviews, found that children attribute happiness to social relations (Thoilliez 2011). Additionally, Fox Eades (2012) reported that in a small sample, sports, friends and family were rated as the top three factors that students identified as making them happy at school.

The WOW responses revealed that participation in various types of activity and social connections are perceived by children and adolescents as key contributors to their happiness. With regard to social connections, children and adolescents attributed their happiness to their relationships with friends, families, and pets. This theme was the second most prevalent theme, accounting for $27 \%$ of all responses.

Overall, children and adolescents most frequently attributed their happiness to the activities they are involved in. The majority of these activities were engaged in with friends or family. Thus, activities may contribute to children's and adolescents' happiness directly, as well as contributing to their happiness via the social elements of engaging in these activities. This is consistent with the findings of Fox Eades (2012) and the view that social relations contribute to children's well-being (see Holder and Coleman 2009, 2015). Even the playing of video games, which were identified by students as related to their happiness, are usually played within a social context (Passmore and Holder 2014). This set of findings is consistent with Schwartz's $(1992,1994)$ model of human values and demonstrates that social-oriented values, in addition to self-oriented values, are developed by a young age.

Many activities that students reported made them feel happy involved physical activity, such as swimming and team sports. These findings parallel reports that active leisure activities are positively correlated with children's happiness (Holder et al. 2009). However, many responses referred to activities that do not promote physical health (e.g., sedentary activities or the consumption of "junk food" snacks, such as hotdogs and candy). This is in line with findings reported by Fox Eades' (2012), in which eating junk food was listed at the fourth highest factor that children identified as making them happy at school. The number of responses referencing eating and/or sedentary activities, such as playing computer games, as a cause of happiness may be of concern given 
the alarming prevalence of overweight and obese children and adolescents (McConnell et al. 2014). Moreover, in terms of well-being, exposure to fast food, including its packaging, has been shown to undermine happiness by decreasing savoring, increasing impatience, and weakening the capacity of well-being interventions (e.g., viewing photos of nature, listening to beautiful music) (House et al. 2014).

Many responses $(11 \%)$ were other oriented, in that children and youth connected their own happiness with the happiness of others. Indeed, just as many responses were related to others' happiness as were related to the students' own feelings of personal happiness. This observation reflects the idea that the concepts of gift-giving (Ruth et al. 1999; Sherry 1983) and sharing (Belk 2010) have been learned by childhood. Our findings are consistent with experimental research showing that toddlers experienced greater happiness when they were giving than when they were receiving (Aknin et al. 2012). Although we did find, as had previous research (e.g., Harter and Whitesell 1989), that children attributed their happiness to receiving as well. Of these responses, half referred to receiving objects while the other half referred to receiving actions indicative of a caring relationship. The latter is in line with telic theories of well-being, which suggest that happiness results from having needs fulfilled (Diener 1984).

Overall, using the WOWs, the present study suggested that children recognize that activities (e.g., sports), followed by relationships (i.e., friends and family) contribute to their happiness, and though junk food was also recognized, it was mentioned by many fewer students. In a study of children that used more traditional methods, similar themes emerged in the same order; sports were the most frequently identified theme, followed by friends and then family. Junk food was mentioned but by far fewer students (Fox Eades 2012). The parallel findings of our work and previous studies, despite substantially disparate methods, provides convergent validity for the WOW method.

Additionally, our results are consistent with previous suggestions that lay theories change with age (Dube et al. 1998; Furnham 2001). Responses written on the WOWs at the kindergarten-elementary school and the junior-high school differed. Older students were more focused on their own activities and feelings as sources of happiness than were younger students who tended towards identifying relationships and otheroriented actions and feelings as sources of personal happiness. It is important to note, however, that any differences in responses on the WOWs between kindergartenelementary school and the junior-high school may not be attributable to age or developmental differences. As referenced in the Other Oriented section above, several of the responses from the younger children referenced a specific program at their school. This program, which aims to promote other-oriented behavior and concepts of benevolence and altruism (see Monin and Jordan 2009), may be enhancing the students' happiness. Thus, any conclusion about age differences are at best preliminary given that only one school at each age range was assessed and these schools differed in many ways in addition to the age of the students.

Findings from this pilot project suggest that there may be sound reasons for helping children to make explicit, and critically think about, their developing theories about happiness and well-being. Thin (2012) conceptualized happiness and well-being as an evaluative kind of conversation and emphasized the dynamic and interactive nature of these constructs. The use of WOWs may serve to invite children and adolescents to share their experience in a community conversation. Responses on the WOWs 
suggested that some students conceptualize happiness as a specific personal feeling or emotion, while others appeared to conceptualize happiness more globally as a general state of being. Adults who can differentiate between nuanced states of both positive and negative emotions exhibit greater resiliency and more effective coping behaviors when faced with difficult emotional situations (Kashdan et al. 2010), and exhibit more effective emotional regulation (Barrett et al. 2001) than adults who rely on global emotional descriptions. Accordingly, if schools and parents structure opportunities for children to develop their ability to make similar distinctions about well-being, they may experience these benefits. The WOWs provided a forum for students to share and express their views on happiness to their peers. The WOWs allow researchers and educators to garner insights from students at a collective level.

\section{Limitations}

As with all research, our study had limitations. Students from only one school representing each age group were assessed. The students at these schools differed in multiple ways in addition to age. Most notably, the older, junior-high, students were all from a faith-based school with less cultural diversity and higher socio-economic status than the students at the kindergarten-elementary school. However, though the cause of the differences between the schools is not known, the fact that the results differed between the two schools suggests that the WOWs are sensitive to community differences. This is important because it suggests that the WOWs might be useful in providing information to researchers to help them develop and customize programs for individual communities.

Additionally, given that the implementation of the WOWs is at the level of the community, not the individual, there are unique limitations to this method that relate to a decrease in experimental control. For example, the WOWs in their current form do not allow for the linking of specific responses to individuals. Therefore, identifying age and gender differences in lay theories was not possible. This may be important because at least in adults and adolescents, there are age and gender differences in lay theories (Bojanowska and Zalewska 2016). Furthermore, students' responses may be influenced by the physical presence of their peers and teachers, as well as the responses on the WOWs written prior to their contribution. By constructing the WOWs to allow for completely voluntary acts of participation, this likely results in a self-selection of those who participate. For example, only students with certain temperaments may have written on the WOWs and thus the responses are not representative of each school's entire population.

However, these limitations are balanced by the value in having a community-based intervention. Currently, most positive psychology interventions are focused on the individual. There is a growing interest in community and organizational well-being (e.g., Fox Eades 2008; Garcea and Linley 2011). Abandoning methods at the community level, because of the resulting decrease in control, will limit the scope of positive psychology applications. Researchers should examine ways of mitigating the extent of the limitations resulting from decreased control. These ways might include assessing students individually before and after employing the WOWs to determine the individual characteristics and levels of well-being of students who wrote on the walls, or who only read the walls, or who did not participate in the WOWs at all. This could help 
characterize who was participating at each level, and if any benefits of the WOWs were moderated by individual differences. In this way, researchers could still develop and assess programs designed to increase well-being that involve the whole school community as Fox Eades (2012) has advocated.

\section{Conclusion}

WOWs potentially represent a new way to engage communities to assess lay theories and enhance components of well-being. Though we only installed the WOWs in schools, they may provide valuable insights if placed at other locations including hospitals, hospices, universities, corporations, and community centers. In addition, there are many different constructs that can be explored with WOWs by using phrases such as "I am grateful for ...", "I am looking forward to ...", "I get personal meaning from ...", or "I feel inspired when ...".

Importantly, the WOWs may be instructive to researchers developing interventions to increase children's well-being. Often interventions are developed using a top-down approach whereby the interventions are developed by researchers who then apply them to a selected group. With the WOWs, researchers could use the qualitative findings to identify the most prominent themes, and then use these themes to guide the development of interventions. For example, the present work suggests that for the kindergartenelementary school assessed, well-being interventions related to social relations might be particularly effective, whereas for the junior-high school assessed, activity-based interventions may be best. Alternatively, for the junior-high school students, interventions may want to focus more attention on the significance of relationships and other-minded actions to happiness. This bottom-up approach is in line with theories of fit which recognize that interventions are most effective when tailored to individuals and communities, rather than taking a "one size fits all" approach (Fordyce 1983; Layous and Lyubomirsky 2012).

The WOW method to assess lay theories represents a complimentary approach to more traditional methods such as one-on-one interviews; it is not intended to replace these valuable methods. Nonetheless, the use of WOWs appear to have several advantages over traditional methods of assessing children's and adolescents' lay theories and conceptualizations of happiness. First, WOWs are a particularly efficient way of collecting responses from large groups. Second, the students seemed to really enjoy the activity, as suggested by their willingness to write on the WOWs without receiving any incentive. Indeed, the WOWs at both schools filled quickly and we had to install additional WOWs. Third, the students' responses were not constrained, as they might be by the nature of the questions or photos used in more structured interview techniques.

Utilization of the WOWs in our pilot project resulted in a rich data set for qualitative analyses which identified five different themes of what children attributed their happiness to: Activities, Relationships, Other Oriented, Personal Feelings, and Receiving. Although preliminary, our findings parallel those from previous studies, despite substantially disparate methods. This suggests convergent validity of the WOWs method. Using the WOWs, similar themes emerged in the same order as themes that emerged from previous studies using more traditional methods. 
Future studies could utilize larger sample sizes from a variety of schools. Perhaps the WOW could serve as an intervention in and of itself; perhaps merely thinking about one's sources of happiness, writing a response on the WOW, and/or reading others' responses could increase happiness. Experimental studies could be conducted comparing pre-WOW and post-WOW levels of happiness; additional studies could utilize grade-matched control groups of students who do not experience a WOW to compare between-group differences in levels of happiness (i.e., WOW-exposed group to nonWOW exposed group). Future studies could also examine inter-generational differences in conceptualizing happiness. "I feel happy when ___ WOWs could be installed in seniors' homes and responses compared to those of the current study. Though the results of the present study should only be viewed as "examples" of what one may find when using this methodology, the WOW is a promising technique for generating bottom-up conceptions of well-being to inform participants and practice.

Acknowledgments The authors acknowledge and thank Camille Selhorst for her help in constructing the WOWs, in recording all of original the line entries from the WOWs, and in coding the responses. This research was supported by a grant from the UBC Okanagan Sustainability Institute to Mark Holder.

Compliance with Ethical Standards The authors declare that they have no conflict of interest and this study was approved by their institution's research ethics board. Prior to the conducting of the research, informed consent was first obtained from the appropriate school boards, principals, teachers and parents, and informed assent was then obtained from all students.

\section{References}

Aknin, L. B., Hamlin, J. K., \& Dunn, E. W. (2012). Giving leads to happiness in young children. PloS One, 7 , e39211.

Barrett, L. F., Gross, J., Christensen, T. C., \& Benvenuto, M. (2001). Knowing what you're feeling and knowing what to do about it: Mapping the relation between emotion differentiation and emotion regulation. Cognition \& Emotion, 15, 713-724.

Belk, R. W. (2010). Sharing. Journal of Consumer Research, 36, 715-734.

Bojanowska, A., \& Zalewska, A. M. (2016). Lay understandings of happiness and the experience of wellbeing: Are some conceptions of happiness more beneficial than others? Journal of Happiness Studies, 17 , 793-815.

Corbin, J., \& Strauss, A. (2008). Basics of qualitative research: techniques to developing grounded theory (3rd ed.). Los Angeles: Sage.

Diener, E. (1984). Subjective well-being. Psychological Bulletin, 95, 542-575.

Diener, E. (2000). Subjective well-being: the science of happiness and a proposal for a national index. The American Psychologist, 55, 34-43.

Diener, M. L., \& Lucas, R. E. (2004). Adults' desires for children's emotions across 48 countries: Associations with individual and national characteristics. Journal of Cross-Cultural Psychology, 35, 525-547.

Dube, L., Jodoin, M., \& Kairouz, S. (1998). On the cognitive basis of subjective well-being analysis: What do individuals have to say about it? Canadian Journal of Behavioral Science, 30, 1-13.

Erdley, C. A., \& Dweck, C. S. (1993). Children's implicit personality theories as predictors of their social judgments. Child Development, 64, 863-878.

Fordyce, M. W. (1983). A program to increase happiness: Further studies. Journal of Counselling Psychology, 30, 483-498.

Fox Eades, J. M. (2008). Celebrating strengths: Building strengths-based schools. Coventry: CAPP Press.

Fox Eades, J. M. (2012). A wellbeing framework for schools. Norwich: Health Education Partnership Ltd..

Furnham, A. (2001). Self-estimates of intelligence: Culture and gender difference in self and other estimates of both general (g) and multiple intelligences. Personality and Individual Differences, 31, 1381-1405.

Furnham, A., \& Cheng, H. (2000). Lay theories of happiness. Journal of Happiness Studies, 1, 227-246. 
Garcea, N., \& Linley, P. A. (2011). Creating positive social change through building positive organizations: Four levels of intervention. In R. Biswas-Diener (Ed.), Positive psychology as social change (pp. 159174). Dordrecht: Springer.

Glaser, B. G. (1992). Basics of grounded theory analysis. Mill Valley: Sociological Press.

Gravetter, F., \& Wallnau, L. (2008). Essentials of statistics for the behavioral sciences (6th ed.). Florence: Thomas Wadsworth.

Harter, S., \& Whitesell, N. R. (1989). Developmental changes in children's understanding of single, multiple and blended emotion concepts. In C. Saarni \& P. L. Harris (Eds.), Children's understanding of emotion (pp. 81-116). Cambridge: Cambridge University Press.

Holder, M. D. (2012). Happiness in children: Measurement, correlates and enhancement of subjective wellbeing. New York: Springer.

Holder, M. D., \& Coleman, B. (2009). The contribution of social relationships to children's happiness. Journal of Happiness Studies, 10, 329-349.

Holder, M. D., \& Coleman, B. (2015). Children's friendships and well-being. In M. Demir (Ed.), Friendship and happiness (pp. 81-97). Amsterdam: Springer Publishing.

Holder, M. D., Coleman, B., \& Sehn, Z. (2009). The contribution of active and passive leisure to children's well-being. Journal of Health Psychology, 14, 378-386.

Holder, M., Coleman, B., \& Wallace, J. (2010). Spirituality, religiousness, and happiness in children aged 812 years. Journal of Happiness Studies, 11, 131-150.

House, J., DeVoe, S. E., \& Zhong, C. (2014). Too impatient to smell the roses: Exposure to fast food impedes happiness. Social Psychological and Personality Science, 5, 534-541.

Huebner, E. S. (1994). Preliminary development and validation of a multidimensional life satisfaction scale for children. Psychological Assessment, 6, 149-158.

Huitema, B. E. (2011). The analysis of covariance and alternatives: Statistical methods for experiments, quasi-experiments, and single-case studies (2nd ed.). Hoboken: John Wiley \& Sons, Inc..

Karafantis, D. M., \& Levy, S. R. (2004). The role of children's lay theories about the malleability of human attributes in beliefs about and volunteering for disadvantaged groups. Child Development, 75, 236-250.

Kashdan, T. B., Ferssizidis, P., Collins, R. L., \& Muraven, M. (2010). Emotion differentiation as resilience against excessive alcohol use: An ecological momentary assessment in underage social drinkers. Psychological Science, 2, 1341-1347.

Laurent, J., Catanzaro, S. J., Joiner, T. E., Rudolph, K. D., Potter, K. I., Lambert, S., et al. (1999). A measure of positive and negative affect for children: Scale development and preliminary validation. Psychological Assessment, 11, 326-338.

Layous, K., \& Lyubomirsky, S. (2012). The how, why, what, when, and who of happiness: Mechanisms underlying the success of positive interventions. In J. Gruber \& J. Moscowitz (Eds.), Positive emotion: integrating the light sides and dark sides (pp. 473-495). New York: Oxford University Press.

Levy, S. R., \& Dweck, C. S. (1999). The impact of children's static vs. dynamic conceptions of people on stereotype formation. Child Development, 70, 1163-1180.

Levy, S., Chiu, C., \& Hong, Y. (2006). Lay theories and intergroup relations. Group Processes \& Intergroup Relations, 9, 5-24.

McConnell, J., Frazer, A., Berg, S., Labrie, T., Zebedee, J., \& Naylor, P. J. (2014). Got health?: A student-led inquiry youth engagement project. Journal of Child and Adolescent Behavior, 2. doi:10.4172 /jcalb.1000153.

McCullough, M. E., Emmons, R. A., \& Tsang, J. (2002). The grateful disposition: A conceptual and empirical topography. Journal of Personality and Social Psychology, 82, 112-127.

Mogilner, C., Kamvar, S. D., \& Aaker, J. (2011). The shifting meaning of happiness. Social Psychological and Personality Science, 2, 395-402.

Mogilner, C., Aaker, J., \& Kamvar, S. D. (2012). How happiness affects choice. Journal of Consumer Research, 39, 429-443.

Monin, B., \& Jordan, J. (2009). Dynamic moral identity: a social psychological perspective. In D. Narva'ez \& D. K. Lapslev (Eds.), Personality, Identity, and Character, Explorations in Moral psychology (pp. 341354). New York: Cambridge.

Mukhopadhyay, A., \& Johar, G. V. (2005). Where there is a will, is there a way? Effects of lay theories of selfcontrol on setting and keeping resolutions. Journal of Consumer Research, 31, 779-786.

Passmore, H.-A., \& Holder, M. D. (2014). Gaming for good: video games and enhancing prosocial behaviour. In J. Graham (Ed.), Video games: Parents' perceptions, role of social media and effects on behavior (pp. 141-166). Nova.

Peterson, C., \& Seligman, M. E. P. (2004). Character strengths and virtues: a classification and handbook. Washington DC: American Psychological Association. 
Piaget, J., \& Garcia, R. (1989). Psvchogenesis and the history of science. New York: Columbia University Press.

Rigby, B. T., \& Huebner, E. S. (2005). Do causal attributions mediate the relationship between personality characteristics and life satisfaction in adolescence? Psychology in the Schools, 42, 91-99.

Robins, R. W., \& Pals, J. L. (2002). Implicit self-theories in the academic domain: implications for goal orientation, attributions, affect, and self-esteem change. Self and Identity, 1, 313-336.

Ruth, J. A., Otnes, C. C., \& Brunel, F. F. (1999). Gift receipt and the reformulation of interpersonal relationships. Journal of Consumer Research, 25, 385-402.

Schwartz, S. H. (1992). Universals in the content and structure of values: theoretical advances and empirical tests in 20 countries. In M. Zanna (Ed.), Advances in experimental social psychology (pp. 1-65). Orlando: Academic Press.

Schwartz, S. H. (1994). Are there universal aspects in the structure and content of human values? Journal of Social Issues, 50, 19-45.

Sherry, J. F. (1983). Gift giving in anthropological perspective. Journal of Consumer Research, 10, 157-168.

Sidana, U. R., Singh, R., \& Srivastava, P. (1976). Social agents in children's happiness. The Journal of Social Psychology, 99, 289-290.

Snyder, C. R., Hoza, B., Pelham, W. E., Rapoff, M., Ware, L., Danovsky, M., et al. (1997). The development and validation of the Children's hope scale. Journal of Pediatric Psychology, 22, 399-421.

Sternberg, R. L., Conway, B. E., Ketron, J. L., \& Bernstein, M. (1981). People's conceptions of intelligence. Journal of Personality and Social Psychology, 41, 37-55.

Thin, N. (2012). Social happiness: Theory into policy and practice. Bristol: Policy Press.

Thoilliez, B. (2011). How to grow up happy: An exploratory study on the meaning of happiness from children's voices. Child Indicators Research, 4, 323-351.

Tong, Y., \& Chiu, C. (2002). Lay theories and evaluations-based organization of impressions: an application of the memory search paradigm. Personality and Social Psychology Bulletin, 28, 1518-1527. 